TITLE:

\title{
ON THE FUNCTIONAL AND COMPARATIVE ANATOMY OF RUNCINA SETOENSIS BABA, AN OPISTHOBRANCH GASTROPOD
}

\section{$\operatorname{AUTHOR(S):~}$}

Ghiselin, Michael T.

\section{CITATION:}

Ghiselin, Michael T.. ON THE FUNCTIONAL AND COMPARATIVE ANATOMY OF RUNCINA SETOENSIS BABA, AN OPISTHOBRANCH GASTROPOD. PUBLICATIONS OF THE SETO MARINE BIOLOGICAL LABORATORY 1963, 11(2): 389-398

\section{ISSUE DATE:}

1963-12-31

URL:

http://hdl.handle.net/2433/175336

RIGHT: 


\title{
ON THE FUNCTIONAL AND COMPARATIVE ANATOMY OF RUNCINA SETOENSIS BABA, AN OPISTHOBRANCH GASTROPOD ${ }^{13}$
}

\author{
Michael T. GHISELIN \\ Hopkins Marine Station \\ Pacific Grove, California, U.S.A.
}

With Plate XVI

The Runcinidae is a family of small cephalaspideans, including the genera Ildica, Runcina and Runcinella. Our anatomical knowledge of Runcina is largely limited to the external features, radula, shell and gastral plates, and to the other internal organs of a single species, $R$. coronata (QuAtrefages). Most anatomical work on Runcina is antique (VAyssière, 1883, 1885; Pelseneer, 1894); the studies of VoN IHERING (1877) and Colosi (1915) contain many questionable statements ( $c f$. HofFMANN, 1932-39). ODHNER's (1924) description of Runcinella is quite brief, and this form differs in various ways from Runcina. The nervous system is especially poorly known, and nothing has ever been published on the functional anatomy of any member of the family Runcinidae.

The animals used in this study were collected from the type locality (BABA, 1954). They inhabit small pools in a zone approximating the upper limits of coralline algae. All observations on feeding and copulation were made in the laboratory. For the anatomical details, gross dissections were made of anaesthetized animals approximately $5 \mathrm{~mm}$ in body length.

The work was done at the Seto Marine Biological Laboratory of Kyoto University. I wish to express my deep gratitude to Dr. Takasi TokIoka for making these facilities available to me, for critical reading of the manuscript, and for many acts of hospitality. Dr. Kikutarô BABA, who has studied this species for many years, has been very generous is criticizing the manuscript and in supplementing and verifying many of my findings.

\section{General Organization}

The shape of the body and the position of the major organs are depicted

1) Contributions from the Seto Marine Biological Laboratory, No. 406.

Publ. Seto Mar. Biol. Lab., XI (2), 1963. (Article 22) 
in Fig. 1; in general organization Runcina setoensis does not deviate greatly from other members of the family. The cephalic shield is, as usual, continuous with the notum, which forms a slight overhang. The heart, the movement of which can be seen by transparency, is simple in structure and consists of an auricle and a ventricle (AU, V). As in Runcinella zelandica (ODHNER, 1924) it is located beside the gill and slightly to the front of it, and is not, as in Runcina coronata (c.f. Hoffmann, 1932-39), displaced toward the anterior. From the ventricle arises the aorta, which, very close to its origin, gives off a branch to the digestive organs, and which extends above the gonad to the head region; these branches correspond, respectively, to the aorta abdominalis and the aorta anterior of Cylichna (Lemche, 1956). The shell has virtually disappeared (BABA, 1954).

The common genital aperture (Fig. 1, C) is located anterior to the gill; to it are connected the ducts of the bursa copulatrix (B), which lies ventrally along the right side, of the female secretory structures of the pallial gonoduct $(\mathrm{FG})$, which occupy the most posterior and ventral portion of the body cavity, and of the gonad (G), which is dorso-lateral and median to anterior. From the common genital opening a ciliated seminal groove extends along the right side of the body, next to the upper surface of the foot, to the male orifice. The male orifice is located on the front of the head, very close to the mouth, Lut not inside it; its position thus differs from that of other species, in which the male orifice is said to be more to the right side of the head, or inside the mouth (CoLosi, 1915). The copulatory apparatus lies on the right side of the body in a ventral position with its free portion extending toward the center; its position displays considerable individual variation.

The anterior part of the head overhangs considerably, so that the mouth is ventral. As is shown in Fig. 2, the anterior portion of the digestive tract consists of a pharynx ( $\mathrm{PH})$, to which are attached paired salivary glands (S), an oesophagus (01), which passes through the highly-concentrated central nervous system, a gizzard (GI), and another oesophageal region (02), which communicates with the digestive gland (Fig. I, D).

The digestive gland occupies a large portion of the body cavity, filling most of the left side of the body behind the gizzard. A smaller lobe (Fig. 1, DL) may be distinguished, which extends beneath the anterior part of the gonad. From the dorsal surface of the digestive gland a relatively straight intestine extends along the right side of the body to the posterior, median anus (A), which is located beneath the posterior rim of the notum, at the base of the gill.

The opening of the opaline gland (Fig. 1, O) is located to the left of the anus. From time to time the animal may be seen to protrude the internal part of this gland through its opening for a brief period. It does this when completely undisturbed, suggesting an excretory function for this structure rather than a defensive one. (cf. EALES, 1921, p. 24 and 45). 
The central nervous system (see below) is a concentrated ring around the anterior part of the digestive system (Fig. 1, CG). Surrounding it are a number of pear-shaped structures which are probably mucous glands (Fig. 1, MU).

\section{Anatomy and Function of the Gut}

As was noted by BABA (1954), Runcina setoensis is unique among the Runcinidae in having a rather degenerate radula. No. reason has been suggested for this, and, except for a dubious statement by Colosi (1915) that Runcina eats ascidians, nothing has been reported on feeding in this family. $R$. setoensis feeds on filamentous algae. Ordinarily it ingests the filaments by placing one end of the filament in its mouth and gradually forcing the filament down its oesophagus, but in some instances the animal may grasp a small filament in the center and force it down bent double. The food is moved into the gut largely by the action of the mandibular elements, which are located on each side of the buccal cavity, and partly movement of the adjacent parts of the head. The degeneration of the radula evidently has resulted from this specialized feeding mechanism in which the radula is no longer necessary.

The food is triturated by the four gastral plates, which are located in the gizzard. These plates rock against one another and crush the food; their muscles are largely concentrated in a mass on the side of the gizzard nearest the digestive gland (Fig. 2, GM). In an animal which has recently fed, spherules of food may be seen in the second oesophagus (02-terminology of LEMCHE, 1956). The mechanism whereby these spherules aae formed is not known; however, the oesophageal diverticulum (OD) may play some rôle. This diverticulum shows no sign of having a secretory function. Its walls are ciliated and it displays a powerful ciliary current. Equally strong ciliary currents may be seen in the first oesophagus (01) and others occur in the second.

The second oesophagus, particularly the portion adjacent to be digestive gland, distends to some degree to function as a crop. The two lobes of the liver communicate via a large space which connects to the second oesophagus. The intestine has a simple structure; its contents are transported by ciliary action.

\section{The Respiratory Apparatus}

The gill, although simple, is of the typically cephalaspidean type, being a plicate gill with with the plicae of the dorsal side occupying a position opposite to the space between the plicae of the ventral surface. This gill thus does not correspond in structure to that of pleurobranchs, to which it bears a superficial resemblance in position. The plicae may bear secondary folds on their surfaces. Respiratory currents sweep acrose the gill from its exterior and lateral surface 
to that nearest the body. These currents result from the action of the cilia on the gill itself, and to some degree also from those covering the space between the dorsum and the foot. The ciliated bands which produce respiratory currents in most cephalaspideans are absent in Runcina setoensis. The number of plicae present on the gill varies, and seems to be proportional to the size of the animal.

\section{The Nervous System}

\section{Sense Organs}

These include the statocysts (see below), the eyes, and the organs of HANCOCK. The eyes (Fig. 1, E) consist of a lens and a cup of black pigment. They are directed toward the dorso-lateral surface and are located some distance from the cephalic ganglia, beneath patches of relatively transparent epithelium. Each organ of HANCOCK extends along an area corresponding to the anterior one third of the dorsum, and consists of about twenty low folds, barely visible in oblique light; their position is unusual, being just under the rim of the dorsum, rather than on the side of the head.

\section{The Central Nervous System}

The central nervous system is highly concentrated into a ring of ganglia around the first oesophagus. It consists of four pairs of ganglia. (Figs. 1, 2 and 3). These include the cerebral ganglia (Fig. 3, LCG, RCG), which are dorsal to the oesophagus, the pedal ganglia (LPG, RPG), which occupy a position somewhat ventral and anterior to the cerebral ganglia, the buccal ganglia (Fig. 2, BG), on the ventral surface of the pharynx near the beginning of the first oesophagus, and two ganglia (Fig. 3, LP+, RP + ), situated posterior to the cerebral ganglia and evidently formed by the fusion of the pleural ganglia with elements of the visceral loop.

Many of the homologies of the nerves and details of innervation could not be worked out short of a study of serial sections. I have succeeded in tracing many of the connections and have found it fruitful to compare my findings with Lemche's exhaustive account (1956) of Cylichna. However, Cylichna has a far less concentrated nervous system than does Runcina, and therefore comparison is difficult. As the structures under consideration are exceedingly delicate, the chances of misinterpretation are considerable, and the present account should be considered provisional until verified by serial sections.

The cerebral ganglia (Fig. 3, LCG, RCG) are interconnected by a very short cerebral commissure (CC). From their lateral surfaces there arise two groups of paired nerves $(C 1, C 2)$ which appear to be essentially equivalent to the nervus labialis and nervus tentacularis respectively in Cylichna. These nerves send branches to the side of the head, their main function probably being innervation of the organ of HANCOCK. A particularly strong branch of the nervus tentacularis (C3) runs along the side of the dorsum. The optic nerve connects to the nervus 
tentacularis, although its precise point of insertion could not be determined. The statocysts (ST) occupy a position between the cerebral and pedal ganglia. A nerve which arises from the lower part of the anterior surface of each cerebral ganglion is probably the cerebro-buccal connective, although it could not be followed in any single specimen.

The buccal ganglia (Fig. 2, BG) are united by a short buccal commissure. Nerves (CB) pass forward along the pharynx. These are apparently the cerebrobuccal connectives.

The pedal ganalia (Fig. 3, LPG, RPG) have a position partly anterior to the cerebral ganglia. The ganglia are so close together that the cerebro-pedal and pleuro-pedal connectives cannot be seen in gross dissection. There is a distinct pedal commissure (PC). Four main nerves were found to arise from each pedal ganglion. Two relatively small ones arise from the anterior, outer, ventral surfaces $(P 1, P 2)$. These appear, from their position and orientation, to correspond to the nervus pedalis anterior and the nervus ventralis respectively of Cylichna. A large nerve $(P 3)$ from the outer, ventral, posterior surface of each pedal ganglion extends for a considerable distance along the side of the body, and is almost certainly Lemche's nervus pedalis lateralis. Finally, a nerve, slightly smaller than the anterior nerves mentioned above, arises anterior to each statocyst. This nerve sends off a small branch near its origin, and is probably the nervus parapodialis of Cylichna, which, as LEMcHe emphasizes, is ill-named.

The ganglia of the visceral loop have coalesced into two masses behind the cerebral ganglia (Fig. 3, LP,$+ \mathrm{RP}+$ ). From each of these masses a long nerve $(A N, S N)$ extends toward the posterior part of the body. The visceral loop $(V L)$, unganglionated and very short, connects the two masses; near the left mass the visceral loop gives off a nerve $(G N)$. The nerve from the mass on the left $(A N)$ and the nerve from the visceral loop $(G N)$ run under the gizzard to a point near the joining of the second oesophagus with the digestive gland. From here one of these $(G N)$ extends to the area of the female glands; I was unable to trace the other any further. The never from the right mass of ganglia extends toward the posterior part of the body, but it could not be traced. From these facts $I$ infer that the left pleural and parietal ganglia have fused into a single body (LP+) incorporating the subintestinal and genital ganglia, while the rest of the ganglia of the visceral loop have fused with the right parietal ganglion. Hence the nerve from the ganglionic mass on the left is the abdominal nerve $(A N)$, and that from the visceral loop is the genital nerve $(G N)$; the nerve from the ganglionic mass on the right $(S N)$ probably includes nerves from the supraintestinal ganglion, although the precise interpretation will require further study. 


\section{The Reproductive System}

The gonad (Fig. 1, G) consists of a number of rounded lobes around a central mass. A separate hermaphroditic ampulla could not be made out in gross dissections, nor could the precise manner of interconnection between the reproductive structures be determined. Contrary to the account of CoLosi (1915) an organ which stores exogenous sperm is present (B). This lies at the end of a thick duct (BD) near the common genital opening (C), and from its position it is probably a bursa copulatrix. ODHNER (1924), without explaining his terminology, refered to the secretory structures of the pallial gonoduct $(\mathrm{FG})$ as the "shell" and mucous glands. I have been able to distinguish three glandular areas, to which $I$ ascribe identifications which must be considered tentative until histochemical work is done on this form. However, Dr. Kikutarô BABA has informed me of staining reactions which do not contradict my findings. The albumen gland (i.e., the structure which secretes the galactogenous layer) is small, posterior, and composed of fine lobules. This is adjacent to a series of a few fine, white folds, which evidently lay down the "membrane" of BABA and Hamatani (1959). The mucous gland makes up most of the glandular mass and is a whitish body composing the anterior part. The glandular mass as a whole is disc-shaped, and has only a few folds.

The copulatory apparatus is diagrammed in Figure 4. The anterior portion is a cirus sac (CS), which evaginates to form the cirus. The cirus is a simple, short, unarmed, truncated cone, without a seminal groove; it is protruded by haemocoelic pressure and retracted by the action of small retractor muscles. Posterior to the cirus sac is a short prostate $(\mathrm{P})$, which has secretory walls; its function is the formation of spermatophores, which may occasionally be seen as a whitish swelling of the prostate. An elongate sperm-storage organ, for which I introduce the term bulbus seminalis (BU), in preference to the misleading term "male seminal vesicle", arises from the base of the prostate and ends blindly; the sperm contained in it become active when placed in sea water. ODHNER (1924) did not find this structure in Runcinella, although it is known in other species of Runcina (CoLosi, 1915).

Copulatory behavior was observed. The attempts at transfer of sperm were usually not successful, and evidently a state of physiological readiness is necessary before these animals will attempt to copulate, since some animals did not show signs of sexual activity, while others attempted copulation repeatedly. Elicitation of copulatory behavior may result from a chemical stimulus, since evagination of the cirus occurs before the animals touch, and since objects in motion do not seem to produce evagination. Large animals ( $5 \mathrm{~mm}$ long) have been seen to display copulatory behavior upon coming in contact with animals $2-1 / 2 \mathrm{~mm}$ long, but in these instances no sperm was transferred. The cirus is 
projected to the anterior, and is applied to the surface of the partner's body. This application does not seem to be wholely random, since the cirus was more frequently applied to the tail and to the right side of the body than elsewhere. When the cirus is finally applied to the common "genital opening, after many unsuccessful attempts, the animal receiving the sperm contracts longitudinally, and after a few seconds the partners separate.

On several individuals two spermatophores were seen attached to one animal. They are minute, pear-shaped structures which protrude from the genital opening. They may be found attached to animals as small as $3 \mathrm{~mm}$ long.

\section{Discussion}

\section{Adaptations to Minuteness}

Runcina is unusually small for a gastropod, evidently being descended from somewhat larger ancestors. In adaptation to this reduction in size a number of modifications in structure are apparent. The movement of materials is largely by ciliary action rather than by muscular activity. This may be seen in the movement of materials by cilia in the gut. The gill is particularly simple. The reproductive system shows simplification in the small number of gonadial lobes and in the paucity of folding in the secretory structures. The great concentration of the ganglia, while partly a result of detorsion and loss of the shell, finds parallels in many groups of small opisthobranchs (Acochlidiacea, Philinoglossa, Pyramidellidae etc.). The radula may have become simplified and reduced partly because it is an inefficient organ in such small forms.

As a final example of adaptation to minuteness, we may consider direct development. Direct development is known in Vayssieria (RISBEC, 1928), Okadaia (BABA, 1937), three species of Runcina (VAyssiere, 1900; BABA and Hamatani, 1959), and in various sacoglossans (Pelseneer, 1899). A number of authors (e.g., LLOYD, 1952) have discussed direct development in opisthobranchs, and this phenomenon is usually attributed to an ecological niche in which the animals are partly isolated from the sea. While not denying the partial applicability of this explanation, I should like to suggest that in these cases direct development results in part from the small size of the animals. All the opisthobranchs in which direct development has been reported are relatively small, and they lay few eggs. BABA (1937) reports that Okadaia elegans lays from 3 to 23 eggs per mass. In Runcina setoensis there are 50 to 100 (BABA and Hamatani, 1959). It seems reasonable to infer that under those ecological conditions where the chances of a larva finding a suitable site for metamorphosis and survival are slight, direct development will be selectively advantageous, and where there are few eggs the survival of any one of them is particularly unlikely. 


\section{The Systematic Position of the Runcinidae}

MAZZARELLI (1893) and others have related Runcina to the Notaspidea, largely because of a superficial similarity in the position of the gill. This interpretation is now of historical interest only, since there are numerous differences in the internal structure. The structure of the gill in $R$. setoensis further argues against such a relationship.

Boettger (1954) derived the Runcinidae from a line of descent leading from the Philine-like forms to the Anaspidea, Soleolifera and Acoela. Boetrger's derivation was supported by arguments based on the structure of the nervous system, including the pattern of fusion of the ganglia. If $m y$ interpretation of the modifications which have occurred in Runcina's visceral loop is correct, then Runcina differs from the Acoela in that the abdominal and genital ganglia are fused to the left side of the central nervous system rather than to the right. This is not to say that BoetTGer's phylogenetic derivation is disproved, but only that it finds no support in the structure of the nervous system, since the common ancestor of the Runcinidae and the Accela would have to be one in which the ganglia were unfused. Indeed, the conditions of the nervous system as described by LEMCHE (1956) for Cylichna are such that the nervous system of Runcina can be derived from something very much like it. On the other hand, the same kind of non-concentrated nervous system may be found in Bulla (MArcus, 1957) and in Haminoea (VAYssière, 1880); in these forms a tendency for uniting of the subintestinal, abdominal and genital ganglia is to be seen, and the conditions which exist in Runcina could easily be derived from such a configuration. In Philinoglossa (MARCUs and MARCUS, 1954), in which the central nervous system is quite concentrated, the subintestinal ganglion and the visceral ganglion are united and lie close to the central nervous system on the left side. Thus it is possible, on the basis of the structure of the nervous system, to argue that Runcina is related to groups of cephalaspideans other than the Philinidae and their close relatives.

In the course of my current investigations into the comparative anatomy of reproductive systems throughout the Opisthobranchia, I have come to the tentative conclusion that the copulatory apparatus of Runcina belongs to a type which has great systematic value. The copulatory apparatus of Runcina closely resembles, both in structure and in mode of function, that of the Bullidae, Atyidae, Cryptophthalmidae and Philinoglossidae, and it is among these forms that the close relatives of the Runcinidae are to be sought.

\section{Summary}

1. The general anatomy is described and compared with that of related forms.

2. R. setoensis feeds on filamentous algae. The feeding mechanism and 
the functional anatomy of the gut are described.

3. The structure of the gill is treated functionally and comparatively.

4. The structure of the highly-concentrated central nervous system is described. It is compared with that of other cephalaspideans and its homologies and evolution are discussed.

5. The reproductive system and copulatory behavior are described. Spermatophores are noted.

6. Various structural peculiarities, including direct development, are ascribed to the small size of the animal.

7. The systematic position is discussed. The structure of the nervous system does not indicate affinity to the Philinidae.

\section{LITERATURE}

BABA, K., 1937. Contribution to the knowledge of a nudibranch, Okadaia elegans BABA. Jap. Journ. Zool., vol. 7, no. 2.

BABA, K., 1954. Runcina setoensis, a new and rare species from the coast of Kii, Middle Japan (Opisthobranchia). Publ. Seto Mar. Biol. Lab., vol. 3, no. 3.

BABA, K., and I. HAMATANI, 1959. The direct development in Runcina setoensis BABA (Opisthobranchia-Cephalaspidea). Publ. Seto Mar. Biol. Lab., vol. 7, no. 2.

Boettger, C. R., 1954. Die Systematik der euthyneuren Schnecken. Verhandl. Deutschen Zool. Gesell., Zool. Anz. Suppl. Bd. 18.

Colosi, G., 1915. Osservazioni anatomo-istologiche sulla Runcina calaritana n. sp. Mem. Accad. Sci. Torino, vol. 21, pt. 5 .

Eales, N. B., 1921. Aplysia. Liverpool Marine Biology Committee Memoir no. 24.

HoffmanN, H., 1932-39. Opisthobranchia, Teil I. In: BronN's Kl. Ord. 3 Bd. II. Abtlg. 3 Buch. Leipzig.

VON IHERING, H., 1877. Vergleichende Anatomie des Nervensystems und Phylogenie der Mollusken. Leipzig.

LemCHE, H., 1956. The anatomy and histology of Cylichna (Gastropoda Tectibranchia). Spolia Zool. Mus. Hauniensis, vol. 16.

Lioyd, H. M., 1952. A study of the reproductive systems of some opisthobranchiate molluscs. Ph. D. Thesis, University of London.

MARCUs, Ev. und Er. MARCUs, 1954. Über Philinoglossacea und Acochlidiacea. Kieler Meeresforsch., Bd. 10, Heft 1.

MARCus, E., 1957. On Opisthobranchia from Brazill (2). Journ. Linn. Soc. London, vol. 43, no. 292 .

Mazzarelli, G., 1893. Richerche sulle Peltidae del Golfo di Napoli. Atti R. Accad. Sci. Fis. Mat. Napoli, vol. 6, ser. 2, no, 4.

Odhner, N. Hj., 1924. New Zealand mollusca. Papers from Dr. Th. Mortensen's Pacific Expedition 1914 16. 19. Vidensk. Meddel. Dansk Naturh. Foren., vol. 77.

Pelseneer, P., 1894. Récherches sur divers opisthobranches. Mém. Sav. étr. Acad. R. Belg., t. 53 .

Pelseneer, P., 1899. La condensation embryogénique chez un nudibranche. Trav. Stat. Zool. Wimereux, t. 7.

Risbec, J., 1928. Contribution a l'étude des Nudibranches Néo-Calédoniens. Faune Colon. Franc., t. 2 .

VAyssière, A., 1880. Récherches anatomiques sur les Mollusques de la famille des Bullidés. Ann. Sci. Nat., Zool., Ge sér., t. 9. 
VAyssiÈre, A., 1883. Récherches anatomiques sur les genres Pelta (Runcina) et Tylodina. Ann. Sci. Nat., Zool., 6e sér., t. 15.

1885. Opisthobranches du golfe de Marseille, $1^{\mathrm{er}}$ partie, Tectibranches. Ann. Mus. Hist. Nat., Marseille, t. 2.

1900. Note sur un nouveau cas de condensation embryogénique observé chez le

Pelta coronata, type de tectibranche. Zool. Anz., Bd. 23.

\section{EXPLANATION OF PLATE XVI}

\section{Runcina setoensis $\mathrm{BABA}$}

Fig. 1. Diagram of general organization, dorsal view. A, anus ; AU, auricle; $\mathrm{B}$, bursa copulatrix; $\mathrm{BD}$, duct of bursa copulatrix; $\mathrm{C}$, common genital opening; CG, left cerebral ganglion; $\mathrm{CS}$; cirus sac; $\mathrm{D}$, digestive gland ; $\mathrm{DL}$, small lobe of digestive gland; E, eye; FG, female glands ; G, gonad ; GI, gizzard ; GL, gill ; HA, HP, anterior and posterior limits of the organ of Hancock; $\mathrm{M}$, male aperture; $\mathrm{MO}$, mouth; $\mathrm{MU}$, a mucous gland; $\mathrm{O}$, opaline gland; $\mathrm{P}$, prostate; $\mathrm{PH}$, pharynx.

Fig. 2. Dissection of anterior part of gut ; ventral, semidiagrammatic. BG, right buccal ganglion; $\mathrm{CB}$, cerebro-buccal connective; GM, muscles of gizzard; 01, 02, first and second oesophageal regions; OD, oesophageal diverticulum; $\mathrm{S}$, salivary gland. (Other letters as in Fig. 1.)

Fig. 3. Central nervous system viewed from the rear and above, semidiagrammatic. $A N$, abdominal nerve ; $C 1$, nervus labialis ; $C 2$, nervus tentacularis ; $C 3$, branch of nervus tentacularis; $C C$, cerebral commissure; $G N$, genital nerve ; LCG, left cerebral ganglion; LPG, left pedal ganglion ; LP + , left ganglionic mass (see text) ; 1 , nervus pedalis anterior; $P 2$, nervus ventralis; $P 3$, nervus pedalis lateralis; $P C$ pedal commissure; RCG, right cerebral ganglion; $\mathrm{RPG}$, right pedal ganglion; $\mathrm{RP}+$, right ganglionic mass (see text); SN, nerve from "RP + " (see text); ST, statocyst; VL, visceral loop.

Fig. 4. Outline diagram of copulatory apparatus. BU, bulbus seminalis; $\mathrm{CS}$, cirus sac; $P$, prostate. 
Publ. Seto Mar. Biol. Lab., XI, 2 (1963)

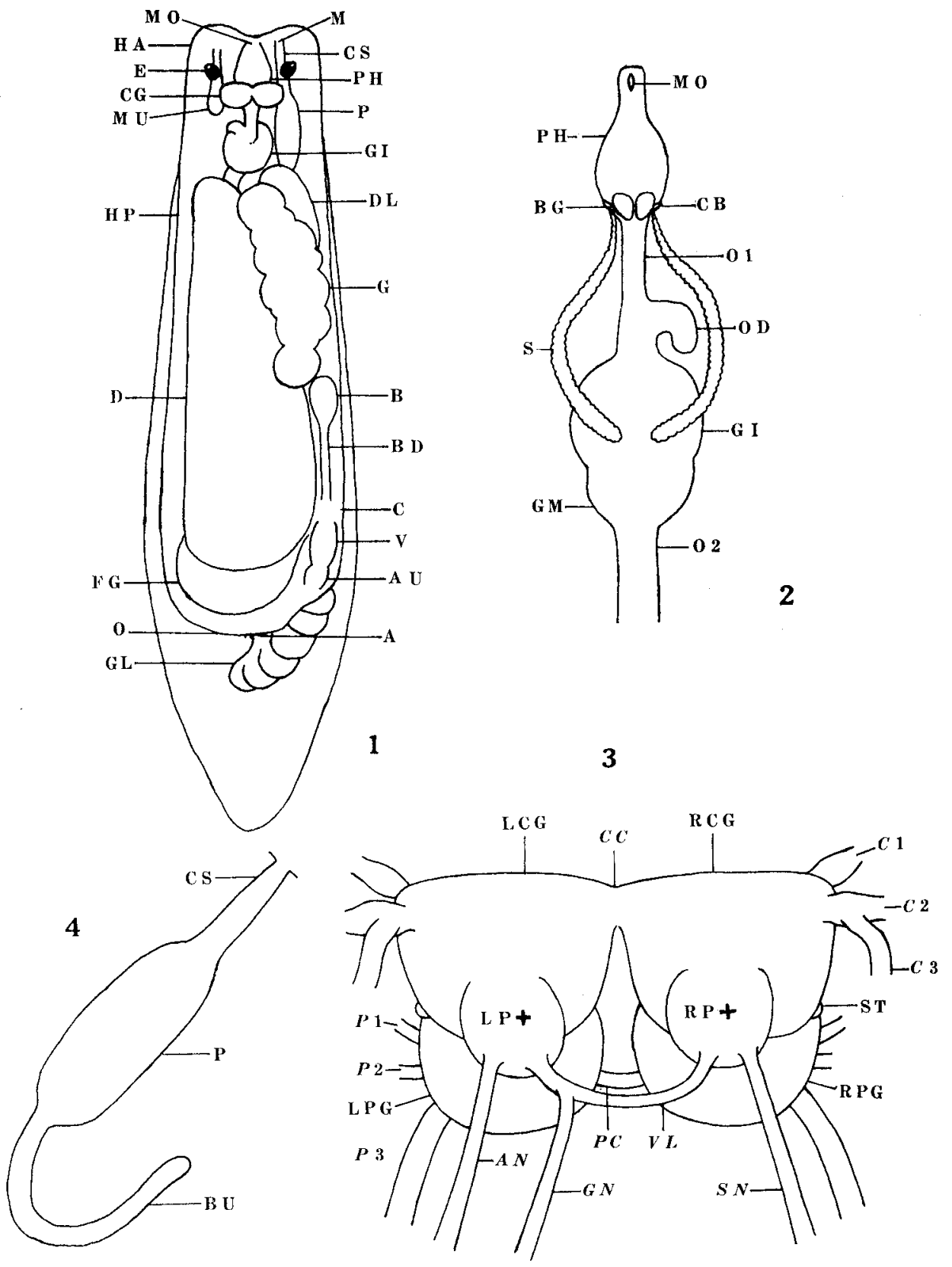

M. Ghiselin: Functional and Comparative Anatomy of Runcina. 